\title{
University Students' Perceptions toward Stuttering according to Mass-Media Experiences
}

\author{
Kyungjae Lee \\ Department of Audiology and Speech-Language Pathology, Daegu Catholic University, Gyeongsan, Korea
}

대중매체 경험에 따른 대학생의 말더듬에 대한 인식

\author{
이 경 재 \\ 대구가톨릭대학교 언어청각치료학과
}

\begin{abstract}
Purpose: Various groups of people may show negative perceptions toward stuttering. One of the reasons for such negative perception is that stuttering is portrayed negatively in mass-media. The primary purposes of the current study were to explore university students' mass-media experiences of stuttering and to determine whether there would be differences in stuttering perception according to such experiences. In addition, the current study tried to determine differences in stuttering perception according to personal factors such as gender and friends and relatives who stutter. Methods: A total of 82 university students (37 male and 45 female; mean age: 21.4 years old) took part in the current study. They completed questionnaires on their mass-media experiences with stuttering. Also, they completed bipolar adjective scales and Public Opinion Survey of Human Attributes-Stuttering, and it was determined whether there would be differences in the responses according to mass-media stuttering experiences, gender, and friends/relatives who stutter. Results: A total of 32 participants (39.0\%) had stuttering mass-media experiences. Even though they showed negative responses toward stuttering portrayed by mass-media, there was no statistically significant difference in the responses according to stuttering mass-media experiences. There was a very limited difference in the responses according to gender and friends/relatives who stutter. Conclusion: The results of the current study suggest that mass-media play a limited role for formation of negative responses toward stuttering. There needs to be further efforts to provide information on stuttering to enhance responses toward stuttering.
\end{abstract}

Key Words: Stuttering, Perception, Mass-media, University student.

Received: September 1, 2019 / Revised: September 26, 2019 / Accepted: October 2, 2019

Correspondence: Kyungjae Lee, Department of Audiology and Speech-Language Pathology, Daegu Catholic University, 13-13 Hayang-ro, Hayang-eup, Gyeongsan 38430, Korea

Tel: +82-53-850-2543 / Fax: +82-53-359-6780 / E-mail: kjlee0119@cu.ac.kr

\section{INTRODUCTION}

말더듬 인식에 대한 연구를 살펴보면 다양한 집단이 말더듬 을 부정적으로 인식한다고 보고하였다(Cooper \& Cooper, 1996; Crowe \& Walton, 1981; White \& Collins, 1984; Woods \& Williams, 1976). 사람들은 말더듬는 사람들은 더 긴장하고, 내향적일 것 같다는 등의 부정적 인식으로 바라본다(Sim, 2000). 이러한 부정적인 인식은 말더듬이 주로 발생하는 학령 전기 아 동과 많은 시간을 보내는 유치원 교사뿐 아니라 초중고교 교

(c) This is an Open Access article distributed under the terms of the Creative Commons Attribution Non-Commercial License (https://creativecommons.org/licenses/by-nc/4.0) which permits unrestricted non-commercial use, distribution, and reproduction in any medium, provided the original work is properly cited.
사, 대학생, 말더듬는 사람에게 임상적인 도움을 제공하는 언어 치료사에게서도 확인된다(Ahn, 2013a, 2013b; Cooper \& $\mathrm{Coo}^{-}$ per, 1996; Kim et al., 2018; Lee, 2013; Sim, 2000). 이러한 말 더듬에 대한 부정적인 인식은 지역, 문화 등과 상관없이 나타나 는 것으로 알려져 있다. 이에 다양한 지역에서의 말더듬에 대한 인식을 표준화된 평가도구를 사용하여 평가하고 이를 비교하 고자 하는 노력도 있었으며 국내에서도 이를 일부 적용하는 연 구가 있었다(Chon, 2016a, 2016b; Lee \& St. Louis, 2014; St. Louis, 2011).

이러한 말더듬는 사람에 대한 부정적인 인식과 태도에 영향 을 주는 요인으로는 우선 말더듬에 대한 교육이 있을 수 있다. 유치원 교사 및 특수교사의 말더듬에 대한 인식이 특수교육 연 
수와 같은 재교육 경험에 따라 유의한 차이를 보이는지에 대해 서는 이견이 있다(Ahn, 2013a, 2013b; Kim, 2016). 이는 대상 자가 경험하는 재교육의 내용 등에 따른 차이로 여겨진다. 이와 관련하여 말더듬에 대한 직접적인 교육이 비록 제한적이기는 하지만 유치원 교사의 말더듬 인식 향상에 긍정적인 영향을 끼 친다는 보고가 있었다(Kim et al., 2018).

이와 더불어 말더듬는 사람과의 접촉 혹인 개인적 친분이나 성별이 말더듬에 대한 인식에 영향을 줄 수 있을 것으로 생각 되나 이와 관련된 연구 역시 비일관적인 결과를 보고하였다. Klassen(2002)은 말더듬는 사람을 친구, 동료, 친척으로 둔 사 람들은 일반인보다 말더듬에 대한 인식이 덜 부정적이라고 보 고하였다. 반면 말더듬 아동 경험 여부에 따른 교사의 말더듬 인식과 관련된 연구는 서로 상반된 결과를 보고하였다. 예를 들어 $\operatorname{Kim}(2016)$ 은 말더듬 아동 담임 경험에 따라 말더듬 인식 에서 유의한 차이가 없었다고 보고하였으며 $\operatorname{Han}(2015)$ 은 제한 적으로 차이가 나타난다고 보고하였다. 또한 성별에 따른 차이 역시 일부 연구는 남성이 더 부정적이라는 보고와 차이가 없다 는 연구가 혼재하였다(Burley \& Rinaldi, 1986; Chon, 2016a, 2016b) 즉, 이와 같은 결과는 말더듬 인식에 영향을 줄 수 있는 요인이 다양한 양상으로 나타날 수 있기에 보다 세부적으로 집 단을 나누어 살펴볼 필요가 있다는 점을 시사한다.

말더듬에 대한 일반인의 부정적 인식은 일반인이 자신의 비 유창성 경험에 근거하여 말더듬을 판단하기 때문이라는 설명 이 있다(MacKinnon et al., 2007). 일반인은 자신이 긴장하였 을 때 비유창성을 경험하기에 이와 같은 자신의 비유창성 경험 에 근거하여 말더듬는 사람은 긴장되어 있다는 것과 같은 부정 적인 인식을 초기에 보일 수 있다. 하지만 말더듬는 사람을 직 접적으로 만나고 이들과 개인적인 경험을 하게 되면 이러한 부 정적인 인식에서 변화가 나타나 말더듬는 사람의 특성을 적절 히 파악하게 되는 것으로 MacKinnon et al.(2007)은 말더듬에
대한 인식을 설명하였다.

이와 더불어 제시되는 또 하나의 원인은 말더듬는 사람이 대 중매체에서 부정적으로 묘사된다는 것이다. 텔레비전, 영화, 도 서 등 다양한 대중매체에서 말더듬는 사람은 부정적으로 묘사 되기에 이러한 대중매체로 말더듬는 사람을 접하는 일반인들 은 말더듬는 사람에 대하여 부정적인 인식을 갖게 된다는 것이 다(Benecken, 1995). 하지만 아직 국내에서 일반인들이 말더듬 는 사람과 관련된 대중매체 경험이 어떠한지에 대해서는 실증 적인 연구가 매우 부족한 편이다. 더불어 성별, 말더듬 친구/친 척 등과 같은 개인적인 특성이 말더듬에 대한 인식에 영향을 줄 것으로 기대되었으나 이와 관련하여 세부 집단을 대상으로 하는 연구 역시 부족한 편이다.

이에 본 연구에서는 대학생들을 대상으로 말더듬는 사람과 관련된 대중매체 경험을 살펴보고 이러한 대중매체 경험에 따 라 말더듬에 대한 인식에서 차이가 나타나는지 살펴보고자 하 였다. 이와 같은 대중매체 경험 이외에도 성별, 말더듬 친구/친 척 등과 같은 개인적 요인에 따라 말더듬에 대한 인식에서 차이 가 나타나는지 살펴보고자 하였다. 이를 통하여 본 연구는 말 더듬 인식 개선을 위한 기초자료를 제공하고자 한다.

\section{MATERIALS AND METHODS}

\section{연구 대상}

본 연구에서는 대구·경북 지역에서 거주하고 있는 평균연령 21.4세[standard deviation $(\mathrm{SD})=1.61]$ 의 대학생 총 82명(남자 37 명, 여자 45명)을 대상으로 말더듬에 대한 인식을 분석하였 다. 참여자의 특성은 Table 1에 제시하였다. 남성 참여자의 평 균연령은 21.6세 $(\mathrm{SD}=2.20)$, 여성 참여자의 평균연령은 21.2세 $(\mathrm{SD}=0.84)$ 였다. 참여자 중 1학년은 22명, 2학년은 22명, 3학년 은 26명, 4학년은 12 명이었다. 고학년으로 올라갈수록 남성 참

Table 1. Participants' information $(n=82)$

\begin{tabular}{|c|c|c|c|}
\hline Grade & Male & Female & Total \\
\hline 1st year & $\begin{array}{c}16 \\
\text { (friends/relatives who stutter: } 5 \text {, } \\
\text { mass-communication experiences: } 3 \text { ) }\end{array}$ & $\begin{array}{c}6 \\
\text { (friends/relatives who stutter: 0, } \\
\text { mass-communication experiences: 3) }\end{array}$ & $\begin{array}{l}22 \\
\text { (friends/relatives who stutter: } 5 \text {, } \\
\text { mass-communication experiences: 6) }\end{array}$ \\
\hline 2nd year & $\begin{array}{c}6 \\
\text { (friends/relatives who stutter: } 1 \text {, } \\
\text { mass-communication experiences: 2) }\end{array}$ & $\begin{array}{l}16 \\
\text { (friends/relatives who stutter: } 5 \text {, } \\
\text { mass-communication experiences: } 8 \text { ) }\end{array}$ & $\begin{array}{l}22 \\
\text { (friends/relatives who stutter: 6, } \\
\text { mass-communication experiences: 10) }\end{array}$ \\
\hline 3rd year & $\begin{array}{c}8 \\
\text { (friends/relatives who stutter: } 2 \text {, } \\
\text { mass-communication experiences: } 3 \text { ) }\end{array}$ & $\begin{array}{l}18 \\
\text { (friends/relatives who stutter: } 4 \text {, } \\
\text { mass-communication experiences: 6) }\end{array}$ & $\begin{array}{l}26 \\
\text { (friends/relatives who stutter: 6, } \\
\text { mass-communication experiences: 9) }\end{array}$ \\
\hline 4 th year & $\begin{array}{c}7 \\
\text { (friends/relatives who stutter: 2, } \\
\text { mass-communication experiences: 5) }\end{array}$ & $\begin{array}{l}5 \\
\text { (friends/relatives who stutter: } 2 \text {, } \\
\text { mass-communication experiences: 2) }\end{array}$ & $\begin{array}{l}12 \\
\text { (friends/relatives who stutter: } 4 \text {, } \\
\text { mass-communication experiences: 7) }\end{array}$ \\
\hline
\end{tabular}


여자의 경우 군 휴학 등의 이유로 여학생과 비교, 연령이 높아 지기에 남녀 참여자의 연령을 일치시키기 위하여 남학생의 경 우 1 학년의 비율이 높았다. 참여자들은 전단지, 구두 모집 등의 방법으로 본 연구에 참여하게 되었다.

모든 참여자는 현재 말더듬 문제가 없으며 과거 말더듬 치료 경험이 없었다고 보고하였다. 또한 그 밖의 다른 말/언어 문제, 심리 문제, 행동 문제 등이 자기보고에 따르면 없었다. 더불어 이들은 모두 언어치료 및 관련 영역을 전공한 학생이 아니었으 며 말더듬 혹은 의사소통장애 관련 과목을 수강한 경험은 없 었다. 또한 참여자 중 21 명은 말을 더듬는 친구/친척이 있으며 61명은 없다고 하였다.

\section{연구 절차}

참여자는 집중할 수 있는 조용한 장소에서 설문지를 작성하 였다. 우선 참여자는 나이, 성별 등과 같은 참여자 기본 정보를 작성하였으며 말더듬에 대한 대중매체 경험 등과 관련된 설문 지에 응답하였다. 또한 말더듬에 대한 인식을 살펴보기 위하여 이분형 형용사 척도(bipolar adjective scale)와 Public Opinion Survey of Human Attributes-Stuttering (POSHA-S) (Lee \& St. Louis, 2014; St. Louis, 2011)을 무순으로 실시하였다.

특히 본 연구에서는 말더듬과 관련된 설명을 제시하지 않고 대상자의 반응 등을 살펴보았다. 이는 참여자들이 일반적으로 가지고 있는 “말더듬"에 대한 인식을 살펴보기 위함이었다.

\section{연구 도구}

우선 말더듬에 대한 대중매체 경험은 설문지를 통하여 살펴 보았다. 설문지에는 말더듬에 대한 대중매체 경험이 있는지, 있 다면 어떠한 종류의 대중매체인지(예: 영화, 드라마, 소설 및 기 타 서적 등)를 작성하고 횟수와 그 대중매체의 내용을 작성하 게 하였다.

말더듬에 대한 인식은 이분형 형용사 척도와 POSHA-S를 실시하여 살펴보았다. 우선 이분형 형용사 척도는 "수줍어함대담함”과 같이 서로 대칭적인 특성을 나타내는 형용사로 이루 어진 척도이다. 이와 같은 이분형 형용사 척도는 말더듬에 대한 인식을 살펴보는 데 타당도와 신뢰도가 입증되어 널리 사용되 었으며 연구자에 따라 6 25항목으로 문항 수가 조절되어 사용 되었다(Healey et al., 2007; Irani \& Gabel, 2008; Lee \& Manning, 2010; Sim, 2000; Woods \& Williams, 1976).

본 연구에서는 $\operatorname{Sim}(2000)$ 의 연구에서 특히 말더듬는 사람 이 7점 척도에서 1 2점 정도로 매우 부정적으로 인식된 10개의 항목을 이용하여 말더듬는 사람에 대한 인식을 평가하였다 (Appendix). 본 연구에서 사용한 항목은 수줍어함-대담함, 조 심함-자신감 있음, 긴장-이완, 민감-둔감, 안절부절-침착, 소극
적-적극적, 회피적-사교적, 두려워함-확신에 참, 내향적-외향 적, 주저함-도전적 등이다. 참여자는 각 항목에 대하여 말더듬 는 사람을 어떻게 생각하는지 7점 척도로 평가하였다. 낮은 점 수는 좌측에 해당하는 특성을, 높은 점수는 우측에 해당하는 특성을 나타내는 것으로 해석하며 점수가 높을수록 긍정적인 인식을 나타내는 것으로 분석한다.

POSHA-S는 다양한 지역에서 관찰되는 말더듬에 대한 인 식을 비교하기 위하여 제시된 평가도구이다(St. Louis, 2011). $\mathrm{POSHA}-\mathrm{S}$ 는 크게 말더듬는 사람에 대한 믿음과 말더듬는 사 람에 대한 반응, 두 영역으로 이루어진다. 말더듬는 사람에 대 한 믿음은 말더듬는 사람의 특성에 대한 믿음(특성), 누구로부 터 도움을 받을 수 있는지(조력자), 말더듬의 원인(원인), 직업과 일상생활 등에서의 말더듬는 사람의 능력(가능성) 등과 관련된 네 하위 영역으로 구성되며, 이 네 하위 영역의 평균점이 말더 듬는 사람에 대한 믿음 점수가 된다. 말더듬는 사람에 대한 반 응은 말더듬는 사람에 대하여 어떻게 도움을 줄 수 있는지(도 움), 말더듬에 대해서 동정이나 거리감 등을 얼마나 느끼는지 (거리감), 말더듬과 말더듬는 사람에 대해서 얼마나 알고 있는 지(지식), 어디에서 말더듬에 대한 지식을 얻었는지(지식 근원) 등을 살펴보는 네 하위 영역으로 구성되며 이 네 영역의 평균 점이 말더듬는 사람에 대한 반응 점수가 된다. 또한 말더듬는 사람에 대한 믿음과 반응, 두 영역의 평균점수로 전체 말더듬 점수를 산출한다. 더불어 말더듬과 비교하기 위하여 비만/정신 질환과 관련된 항목도 포함한다.

본 연구에서는 Lee \& St. Louis(2014)의 번역본을 사용하였 다. 참여자는 각 항목에 대하여 예/아니오, 5점 척도 등으로 다 양하게 답변을 하였다. 이러한 답변은 St. Louis(2011)가 제시한 표준적인 변환 과정을 거쳐서 $+100 ~-100$ 점으로 변환되는데 높은 수치가 각 항목에 대한 더 긍정적인 반응으로 해석된다.

본 연구에서 사용한 설문지 등의 내용이 매스컴 말더듬 경험 등을 평가하는 데 적절한지와 관련하여 언어병리학 관련 박사 과정 수료 이상의 학력이며, 국가자격증을 소지한 세 명의 언어 재활사에게 타당도를 7점 척도(1점: 매우 타당하지 않다, 7점: 매우 타당하다)로 평가하게 하였다. 평가 결과 평균 6.00(SD: $1.07)$ 으로 나타나 본 연구에서 사용한 도구는 적절한 것으로 판단되었다.

\section{통계 분석}

본 연구에서는 우선 말더듬과 관련된 대중매체 경험을 기술 통계를 사용하여 살펴보았다. 이후 말더듬과 관련된 대중매체 경험 유무, 성별, 말더듬 친구/친척 유무 등에 따라서 이분형 형용사 척도와 POSHA-S에서 유의한 차이가 나타나는지 독 립 $t$ 검증을 사용하여 살펴보았다. 


\section{RESULTS}

\section{말더듬과 관련된 대중매체 경험 분석}

본 연구 참여자 82 명 중 대중매체에서 말더듬을 경험한 참여 자는 총 32명(39.0\%)이었다. 이 중 남성 참여자는 13명(35.1\%), 여성 참여자는 19 명(42.2\%)으로 여성 참여자의 말더듬 대중매 체 경험이 조금 더 높은 편이었다.

말더듬과 관련된 내용을 접한 대중매체 유형은 우선 영화가 26건(예: 킹스 스피치, 맨발의 기봉이, 말아톤 등)으로 가장 많았 다. 이어서 드라마 12 건(예: 시간 여행자, 굿 닥터 등), 텔레비전 12건(예: 김현철, 정치 토론 등), 책/잡지 5건(예: 교과서, 꼬마 난 장이 미짓 등), 인터넷 2건(예: 웹툰 등), 기타 1 건 등의 순이었다.

대중매체에서 말더듬을 경험하고 받은 느낌으로는 답답함이 9명으로 가장 많았으며, 별다른 느낌이 없음 4명, 긴장감과 의 사소통 어려움이 각 3 명, 궁금/신기하다, 불편, 조급, 안타까움 등이 각각 2 명이었다. 기타 의견으로는 무섭다 등이 있었다.

Table 2. Means (standard deviation) and independent $t$ test results of Bipolar Adjective Test according to mass-communication stuttering experiences

\begin{tabular}{lccr}
\hline \multicolumn{1}{c}{ Item } & Yes & No & \multicolumn{1}{c}{$t$} \\
\hline Shy-bold & $3.2(1.1)$ & $3.0(1.1)$ & 0.730 \\
Self conscious-self assured & $3.3(1.5)$ & $3.3(1.3)$ & 0.040 \\
Tense-relaxed & $3.0(1.4)$ & $3.1(1.2)$ & -0.520 \\
Sensitive-insensitive & $3.0(1.3)$ & $3.4(1.0)$ & -1.790 \\
Nervous-calm & $3.3(1.4)$ & $3.4(1.4)$ & 0.266 \\
Withdrawn-outgoing & $3.6(1.3)$ & $3.3(1.4)$ & 1.511 \\
Unfriendly-friendly & $3.5(1.4)$ & $3.4(1.6)$ & 0.240 \\
Afraid-confident & $3.4(1.2)$ & $3.4(1.1)$ & -0.021 \\
Introverted-extroverted & $3.5(1.2)$ & $3.1(1.1)$ & 1.238 \\
Hesitant-daring & $3.3(1.3)$ & $3.4(1.1)$ & -0.179 \\
\hline
\end{tabular}

Table 3. Means (standard deviation) and independent $t$ test results of POSHA-S according to mass-communication stuttering experiences

\begin{tabular}{lrcc}
\hline \multicolumn{1}{c}{ Item } & \multicolumn{1}{c}{ Yes } & No & \multicolumn{1}{c}{$t$} \\
\hline Traits & $14.6(65.0)$ & $22.0(65.2)$ & -0.503 \\
Help & $-1.0(31.1)$ & $-8.7(30.7)$ & 1.091 \\
Cause & $26.6(39.5)$ & $23.3(35.3)$ & 0.386 \\
Potential & $46.9(24.4)$ & $46.5(36.8)$ & 0.051 \\
Beliefs & $21.7(18.2)$ & $20.8(20.8)$ & 0.212 \\
Helping & $28.1(39.1)$ & $23.7(40.1)$ & 0.495 \\
Distance & $-18.9(40.0)$ & $-4.0(40.3)$ & -1.643 \\
Source & $-18.8(99.8)$ & $-38.0(87.8)$ & 0.015 \\
Knowledge & $-45.8(44.3)$ & $-53.8(45.7)$ & 0.998 \\
Self reaction & $-21.6(22.7)$ & $-21.2(24.3)$ & 0.516 \\
Overall stuttering score & $0.0(17.4)$ & $-0.2(17.2)$ & 0.965 \\
Obese/mental disease & $-48.4(27.4)$ & $-41.3(29.1)$ & 0.525 \\
\hline
\end{tabular}

POSHA-S: Public Opinion Survey of Human Attributes-Stuttering

\section{말더듬 대중매체 경험에 따른 인식의 차이}

말더듬과 관련된 대중매체 경험 유무에 따른 이분형 형용사 척도 결과는 Table 2 와 같다. 총 10 개의 항목 중 말더듬 대중매 체 경험 유무에 따라 유의한 차이를 보인 항목은 없었다.

말더듬과 관련된 대중매체 경험 유무에 따른 POSHA-S 결 과는 Table 3 과 같다. 대중매체 경험 유무에 따라 전체 말더듬 점수, 말더듬에 대한 믿음 점수, 반응 점수는 통계적으로 유의 한 차이가 나타나지 않았다. 또한 각 하위 영역에서도 통계적으 로 유의한 차이는 나타나지 않았다.

\section{성별에 따른 인식의 차이}

성별에 따른 이분형 형용사 척도 결과는 Table 4 와 같다. 총 10 개의 형용사 항목 중 성별에 따라 유의한 차이를 보인 항목 은 없었다.

성별에 따른 POSHA-S 결과는 Table 5와 같다. 성별에 따라 전체 말더듬 점수, 말더듬에 대한 믿음 점수, 반응 점수는 통계 적으로 유의한 차이가 나타나지 않았다. 하지만 말더듬에 대한 반응의 하위 영역인 거리감에서만 통계적으로 유의한 차이가 나 타났다. 남성의 거리 평균점수는 $0.15(\mathrm{SD}=45.8)$, 여성은 -17.8 $(\mathrm{SD}=34.1)$ 로 남성이 더 긍정적이었다 $\left(t_{(80)}=1.995, p=0.049\right)$.

\section{말더듬 친구/친척 여부에 따른 인식의 차이}

말더듬 친구/친척 여부에 따른 이분형 형용사 척도 결과는 Table 6 과 같다. 총 10 개의 형용사 항목 중 말더듬 친구/친척 여부에 따라 유의한 차이를 보인 항목은 없었다.

말더듬 친구/친척 여부에 따른 POSHA-S 결과는 Table 7과 같다. 유의한 차이를 보인 항목은 지식 근원과 지식 항목이었다. 우선 말더듬 친구/친척이 있는 참여자의 지식 근원 평균은 33.3 $(\mathrm{SD}=96.6)$, 없는 참여자의 평균은 $-52.5(\mathrm{SD}=80.8)$ 로 이러한 차이는 통계적으로 유의하였다 $\left(t_{800}=3.987, p<0.01\right)$. 또한 말더 듬 친구/친척이 있는 참여자의 지식 평균점수는 $-18.1(\mathrm{SD}=$

Table 4. Means (standard deviation) and independent $t$ test results of Bipolar Adjective Test according to gender

\begin{tabular}{lccc}
\hline \multicolumn{1}{c}{ Item } & Male & Female & $t$ \\
\hline Shy-bold & $3.2(1.2)$ & $3.0(1.2)$ & 0.568 \\
Self conscious-self assured & $3.5(1.5)$ & $3.2(1.2)$ & 1.167 \\
Tense-relaxed & $3.3(1.3)$ & $2.9(1.3)$ & 1.774 \\
Sensitive-insensitive & $3.3(1.1)$ & $3.3(1.1)$ & -0.291 \\
Nervous-calm & $3.5(1.4)$ & $3.2(1.3)$ & 0.988 \\
Withdrawn-outgoing & $3.4(1.2)$ & $3.4(1.1)$ & 0.101 \\
Unfriendly-friendly & $3.5(1.3)$ & $3.4(1.2)$ & 0.443 \\
Afraid-confident & $3.6(1.1)$ & $3.3(1.1)$ & 1.368 \\
Introverted-extroverted & $3.2(1.3)$ & $3.3(1.1)$ & -0.374 \\
Hesitant-daring & $3.6(1.2)$ & $3.2(1.1)$ & 1.721 \\
\hline
\end{tabular}


Table 5. Means (standard deviation) and independent $t$ test results of POSHA-S according to gender

\begin{tabular}{lrcc}
\hline \multicolumn{1}{c}{ Item } & Male & Female & $t$ \\
\hline Traits & $23.4(68.4)$ & $15.6(62.2)$ & 0.545 \\
Help & $-7.2(30.6)$ & $-4.4(31.5)$ & -0.401 \\
Cause & $31.5(35.5)$ & $18.9(37.2)$ & 1.563 \\
Potential & $49.3(32.0)$ & $44.4(32.8)$ & 0.678 \\
Beliefs & $24.2(20.4)$ & $18.6(19.0)$ & 1.299 \\
Helping & $16.7(41.6)$ & $32.6(36.7)$ & -1.840 \\
Distance & $-0.15(45.8)$ & $-17.8(34.1)$ & $1.995^{*}$ \\
Source & $-29.7(90.9)$ & $-31.1(94.9)$ & 0.067 \\
Knowledge & $-48.6(43.7)$ & $-52.4(46.6)$ & 0.387 \\
Self reaction & $-18.8(23.6)$ & $-23.5(23.6)$ & 0.896 \\
Overall stuttering score & $2.7(17.8)$ & $-2.4(16.4)$ & 1.369 \\
Obese/mental disease & $-40.3(34.0)$ & $-47.2(23.0)$ & 1.094 \\
\hline
\end{tabular}

${ }^{*} p<0.05$. POSHA-S: Public Opinion Survey of Human AttributesStuttering

Table 6. Means (standard deviation) and independent $t$ test results of Bipolar Adjective Test according to having friedns/relatives who stutter

\begin{tabular}{lccc}
\hline \multicolumn{1}{c}{ Item } & Yes & No & $t$ \\
\hline Shy-bold & $3.2(1.1)$ & $3.0(1.1)$ & 0.773 \\
Self conscious-self assured & $3.5(1.3)$ & $3.3(1.4)$ & 0.664 \\
Tense-relaxed & $3.2(1.3)$ & $3.0(1.3)$ & 0.733 \\
Sensitive-insensitive & $3.3(1.4)$ & $3.3(1.0)$ & 0.312 \\
Nervous-calm & $3.4(1.4)$ & $3.3(1.4)$ & 0.337 \\
Withdrawn-outgoing & $3.7(1.3)$ & $3.3(1.2)$ & 1.291 \\
Unfriendly-friendly & $3.6(1.6)$ & $3.4(1.1)$ & 0.609 \\
Afraid-confident & $3.4(1.3)$ & $3.4(0.9)$ & 0.015 \\
Introverted-extroverted & $3.6(1.4)$ & $3.2(1.1)$ & 1.377 \\
Hesitant-daring & $3.4(1.2)$ & $3.3(1.2)$ & 0.394 \\
\hline
\end{tabular}

38.1), 없는 참여자의 평균점수는 $-61.9(\mathrm{SD}=41.9)$ 로 이러한 차이 역시 통계적으로 유의하였다 $\left(t_{(80)}=4.226, p<0.01\right)$. 이러 한 결과는 말더듬 친구 혹은 친척이 있는 사람이 그렇지 않은 사람보다 말더듬과 관련된 정보를 더 많은 곳에서 얻으며 그러 한 지식의 수준 역시 더 높다는 점을 나타낸다.

\section{DISCUSSIONS}

본 연구는 대중매체에서의 말더듬 관련 경험에 따라 대학생 의 말더듬에 대한 인식에서 차이가 있는지 살펴보고자 하였다. 더불어 성별, 말더듬 친구/친척 등의 개인적 특성에 따라 말더 듬에 대한 인식에서 차이가 있는지 살펴보았다. 연구결과 본 연 구 참여자의 $1 / 3$ 이상이 말더듬 관련 매스컴 경험이 있었으나 이러한 매스컴을 통한 말더듬 경험에 따른 대학생의 말더듬 인 식은 통계적으로 유의한 차이를 보이지 않았다. 또한 기타 다른 개인적인 특성에 따른 말더듬에 대한 인식의 차이 역시 제한적 이었다. 이를 보다 자세히 논의하면 다음과 같다.
Table 7. Means (standard deviation) and independent $t$ test results of POSHA-S according to having friends/relatives who stutter

\begin{tabular}{lrcc}
\hline \multicolumn{1}{c}{ Item } & Yes & No & $t$ \\
\hline Traits & $20.6(70.3)$ & $18.6(63.4)$ & 0.125 \\
Help & $-3.2(32.2)$ & $-6.6(30.3)$ & 0.431 \\
Cause & $24.6(47.0)$ & $24.6(33.0)$ & 0.001 \\
Potential & $46.4(39.0)$ & $46.7(30.1)$ & -0.036 \\
Beliefs & $22.1(20.8)$ & $20.8(19.5)$ & 0.257 \\
Helping & $11.9(47.5)$ & $30.1(35.7)$ & -1.840 \\
Distance & $-22.0(34.5)$ & $-5.7(41.9)$ & -1.605 \\
Source & $33.3(96.6)$ & $-52.5(80.8)$ & $3.987^{*}$ \\
Knowledge & $-18.1(38.1)$ & $-61.9(41.9)$ & $4.226^{*}$ \\
Self reaction & $-21.6(21.7)$ & $-21.3(24.4)$ & -0.036 \\
Overall stuttering score & $0.3(14.6)$ & $-0.3(18.0)$ & 0.123 \\
Obese/mental disease & $-50.8(25.9)$ & $-41.8(29.2)$ & -1.251 \\
\hline
\end{tabular}

${ }^{*} p<0.01$. POSHA-S: Public Opinion Survey of Human AttributesStuttering

본 연구결과를 통하여 참여자의 상당수가 말더듬과 관련된 내용을 매스컴에서 접하였다는 점을 알 수 있었으나 이들이 말 더듬에 대하여 적절한 지식이 있는지에 대해서는 추가적인 연 구가 필요할 것이다. 전술하였듯이 본 연구 참여자의 약 $1 / 3$ 이 상이 매스컴에서 말더듬을 경험하였다고 보고하였다. 연구자에 따라 이견이 있을 수는 있으나 말더듬 출현율은 대략적으로 $1 \%$ 정도라고 여겨진다(Shimada et al., 2018). 이처럼 상대적으 로 낮은 발생률과 비교, 본 연구 참여자들이 매스컴을 통하여 말더듬을 경험한 비율은 높은 편이었다. 또한 이는 본 연구 참 여자 중 약 $1 / 4$ 이 말더듬는 친구 혹은 친척을 가지고 있다고 보 고한 것과 비교하여도 높은 수치이다. 이와 관련하여 본 연구 참여자가 제시한 매스컴의 구체적인 내용을 살펴보면 언어병리 학에서 일반적으로 제시하는 말더듬과는 다른 내용이 주를 이 루었다. 예를 들어 말더듬는 사람을 주로 다루는 킹스 스피치 와 같은 영화를 제시한 참여자도 있었으나 맨발의 기봉이, 말 아톤, 굿 닥터 등과 같이 다른 장애를 보이면서 말의 비유창성 을 함께 보이는 경우에도 참여자들은 말더듬이라고 판단하였 다. 즉 본 연구결과는 일반인들은 말의 비유창성을 보이는 여 러 다양한 장애를 보이는 집단을 모두 말더듬이라고 판단한다 는 점을 시사한다. 이와 관련하여 본 연구에 참여한 모든 대학 생들은 언어병리학을 전공하지 않았으며 의사소통장애 관련 과목을 수강한 경험이 없었다. 이러한 특성 등으로 인하여 본 연구 참여자들이 가지고 있는 말더듬에 대한 지식에서 부정확 한 점이 관찰되었을 수 있다. 이와 관련하여 여러 연구들이 다 양한 집단의 사람들이 말더듬에 대하여 부적절한 지식 수준을 보이고 있다고 보고하였다(Ahn, 2013a, 2013b; Kim, 2016). 이 에 후속연구에서는 일반인들이 말더듬에 대하여 가지고 있는 지식 정도 역시 고려하여 연구할 필요가 있을 것이다. 
본 연구결과는 대중매체에서 묘사되는 말더듬에 대하여 일 반인들은 부정적인 인식을 갖을 수 있다는 점을 시사한다. 전 술하였듯이 본 연구의 참여자들이 말더듬이라고 생각하였던 대중매체의 내용은 일반적인 말더듬이 아니었으며, 이러한 대중 매체를 접한 본 연구의 참여자들은 답답함 등과 같은 부정적인 느낌을 받았다고 보고하였다. 이는 말더듬에 대한 일반인의 고 정관념일 수 있지만 매스컴에서 말더듬는 사람들이 묘사되는 방식에 의한 것일 수도 있다. 예를 들어 Evans \& Williams (2015)는 영화에서 말더듬이 어떻게 묘사되는지 조사하였는데 많은 영화에서 말더듬는 사람이 희극 역할, 낮은 인생 만족도, 사회적, 정신적 등에서 문제가 있는 사람 등으로 묘사되었으며 일부의 영화에서만 긍정적으로 묘사되었다고 보고하였다. 전술 하였듯이 본 연구 참여자가 경험한 매스컴 내용은 다양한 다 른 장애와 동반된 상황이 많았기에 이렇게 대중매체에서 묘사 된 말더듬에 대해 본 연구 참여자는 부정적인 인식을 보였던 것으로 판단된다. 이와 관련하여 후속연구에서는 국내 도서와 매스컴 등에서 말더듬이 어떻게 묘사되고 있는지 살펴볼 수 있 을 것이다. 또한 이러한 부정적인 대중매체의 말더듬 묘사를 줄 이기 위해 보다 활발히 말더듬에 대한 인식 개선 활동을 전개 해야 할 것이다. 예를 들어 말더듬의 특성, 원인 등과 같은 기본 정보와 관련된 내용을 일반인들이 보다 쉽게 접근할 수 있도록 다각적으로 제공하여야 할 것이다.

비록 대중매체에서 묘사된 말더듬에 대해서는 부정적인 인 식을 보였으나 이러한 경험 유무에 따라 전반적인 말더듬의 인 식에서는 유의한 차이가 관찰되지 않았다. 이는 말더듬의 대중 매체 노출 빈도 등과 관련이 있을 것으로 생각된다. 비록 본 연 구 참여자 중 $1 / 3$ 이상이 대중매체에서 말더듬을 경험하였으나 그 빈도는 일회성인 것으로 추측된다. 이에 후속연구에서는 대 중매체에서의 말더듬 경험 빈도 등을 고려한 인식 연구가 필요 할 것이다. 또한 본 연구에서는 상대적으로 소수의 참여자를 대 상으로 하였기에 후속연구에서는 보다 더 많은 참여자를 대상 으로 매스컴 영향을 살펴볼 필요가 있을 것이다.

본 연구결과는 성별에 따른 말더듬 인식의 차이는 제한적이 며 비일관적일 수 있다는 점을 시사한다. 이분형 형용사 척도 10 문항 중에서 성별에 따른 유의한 차이가 있는 문항은 없었 다. POSHA-S의 전체 말더듬 점수, 그리고 그 두 하위 영역인 말더듬에 대한 믿음과 반응에서도 역시 성에 따른 차이는 통계 적으로 유의하지 않았다. 다만 말더듬에 대한 반응의 하위 영 역인 거리감에서 성에 따른 차이가 유의하였다. 예를 들어 말더 듬는 사람에 대해서 느끼는 거리감 항목에서는 남성의 점수가 여성보다 높아 거리감을 더 적게 느끼는 것으로 나타났다. 이와 관련하여 남성이 여성보다 더 부정적인 인식을 보이거나 혹은 성별에 따라 유의한 차이가 나타나지 않는다는 이전 연구가 있
었다(Burley \& Rinaldi, 1986; Chon, 2016a, 2016b). 이러한 이 전 연구와 본 연구의 차이는 대상자 집단의 구성의 차이에 기인 할 수 있다. 예를 들어 본 연구는 대학생으로 참여자를 한정하였 으나 이전 연구는 대학생 이외의 일반인 등을 참여자로 하였다. 즉 이와 같은 결과는 말더듬에 대한 인식의 성에 따른 차이는 제한적일 수 있으며 이러한 성에 따른 차이 역시 대상자의 연령, 직업 등에 따라 달라질 수 있음을 시사한다.

말더듬 친구/친척 여부에 따른 말더듬에 대한 인식 역시 일부 항목에서 긍정적인 형태로 나타났다. 구체적으로는 이분형 형용 사 척도에서는 유의한 차이가 관찰되지 않았으나 POSHA-S의 지식 근원(knowledge source)과 지식(knowledge/experience) 에서 말더듬 친구/친척이 있는 참여자의 결과가 더 긍정적이었 다. 이러한 결과는 말더듬 친구 등과 같은 개인적인 경험이 말 더듬 인식에 긍정적인 영향을 준다는 Klassen(2002)의 연구와 유사한 내용이며, 말더듬는 사람을 직접적으로 경험하면서 보 다 더 적절한 방식으로 말더듬에 대한 인식을 가지게 된다는 MacKinnon et al.(2007)의 이론을 지지한다. 즉 본 연구에 참여 한 말더듬 친구 혹은 친척이 있는 사람은 그렇지 않은 사람보 다 말더듬과 관련된 정보를 더 다양한 곳에서 알게 되었으며, 이러한 정보와 말더듬 친구 혹은 친척과의 지속적인 접촉으로 인하여 말더듬에 대한 지식 역시 높은 수준이 된 것으로 추측 된다. 후속연구에서는 말더듬 친구 혹은 친척의 수 등에 따라 이러한 인식에서도 차이가 나타나는지 살펴볼 수 있을 것이다.

본 연구의 결과를 본 연구에서 사용한 유사한 평가도구를 이용한 이전 연구와 간접적으로 비교하면 다음과 같다. 우선 이 분형 형용사 척도 결과를 살펴보면 본 연구의 참여자는 이전 연 구와 비교, 상대적으로 긍정적인 인식을 보였다. 본 연구에서는 $\operatorname{Sim}(2000)$ 의 연구에서 일반 성인이 1 2점 정도의 점수를 부여 한, 즉 부정적인 인식을 보이는 10 개의 항목을 사용하였다. 하지 만 본 연구의 참여자들은 대부분의 항목에서 3점 정도를 보였다. 본 연구에서 3점 이하의 결과를 보인 항목은 한 항목에 불과하 였는데 성별에 따른 차이를 살펴보았을 때 여성이 "긴장-이완" 항목에서 2.9 를 보였다. 즉 이러한 결과는 현재 일반 대학생의 말 더듬에 대한 인식이 부정적일 수는 있으나 과거의 일반 성인과 비교, 긍정적으로 변화하였을 가능성을 제시한다.

비록 과거와 비교, 현재 일반 대학생의 말더듬에 대한 인식에 서 긍정적인 변화가 있었다고 하더라도 아직 국내의 말더듬에 대한 인식은 해외와 비교, 다소 부정적이라는 점을 본 연구결 과는 시사한다. 매스컴을 통하여 말더듬을 경험한 본 연구 참 여자의 POSHA-S 말더듬에 대한 믿음 평균점수는 21.7, 자기 반응 평균점수는 -21.6 , 전체 말더듬 평균점수는 0.0 이었다. 반 면 여러 해외 연구결과의 말더듬에 대한 믿음의 중위값은 31 , 자기반응 중위값은 -5 , 전체 말더듬 중위값은 8 이었다 $(\mathrm{St}$. 
Louis, 2011). POSHA-S 점수는 높을수록 긍정적인 것으로 해 석하기에 본 연구에 참여한 말더듬 매스컴 경험자의 인식이 해 외 중위값과 비교, 부정적인 것으로 해석할 수 있다. 이에 국내 말더듬에 대한 인식의 전반적인 향상과 관련된 노력이 지속적 으로 이루어져야 할 것이다.

본 연구의 제한점과 후속연구에 대한 제안은 다음과 같다. 우선 본 연구 참여자의 말더듬에 대한 매스컴 경험은 매우 다 양하였기에 이후 연구에서는 보다 통일된 특성을 지닌 집단을 대상으로 연구를 진행하여야 할 것이다. 예를 들어 본 연구에 서는 언어병리학을 전공하지 않았으며 말더듬이나 의사소통장 애 관련 과목을 수강하지 않은 대구 및 경북 지역의 대학생을 대상으로 하였다. 하지만 전공, 지역 등에 따라서 인식이 달라 질 수 있으므로 후속연구에서는 이와 같은 특성을 통제하여 실험을 진행하여야 할 것이다. 또한 본 연구에서 말더듬 대중매 체 경험이 있는 것으로 분류된 집단은 그 경험의 양과 질이 매 우 다양하였다. 이에 후속연구에서는 직접 말더듬과 관련된 대 중매체를 소개한 후 이에 따른 말더듬 인식의 차이를 살펴보거 나 경험한 대중매체의 질과 양에 따라 말더듬 인식을 살펴보는 일이 필요할 것이다.

본 연구에서는 말더듬 인식에 영향을 주는 개인적 특성으로 성별 등과 같이 매우 제한된 요인만 사용하였다. 이에 후속연구 에서는 보다 다수의 참여자를 대상으로 다양한 특성을 살펴보 고 이러한 특성들 사이의 상호작용을 살펴볼 수 있을 것이다. 예 를 들어 의사소통장애 관련 과목 수강 여부, 언어치료 전공 여 부 등과 같은 요인에 따른 인식 차이를 살펴볼 수 있을 것이다.

본 연구는 대중매체에서 그려지는 말더듬에 대하여 일반 대 학생이 부정적인 인식을 보일 수는 있으나 전체적으로 이러한 말더듬 매스컴 경험이 말더듬 인식에 유의한 차이를 야기시키 지는 않았다는 점을 시사한다. 더불어 본 연구결과는 비록 과 거와 비교, 말더듬에 대한 인식에서는 변화가 있었을 수는 있으 나 여전히 해외와 비교, 다소 부정적인 인식을 보인다는 점 역 시 시사한다. 이에 말더듬의 특성, 말더듬과 관련된 언어치료사 의 역할 등과 관련된 정보를 일반인들이 보다 더 쉽게 접할 수 있도록 추가적인 노력이 필요할 것이다.

중심 단어 : 말더듬·인식·대중매체·대학생.

\section{Ethical Statement}

The study was approved by the Institutional Review Board of Daegu Catholic University (CUIRB-2018-0027).

\section{Acknowledgments}

The authors thank to the participants.

\section{Declaration of Conflicting Interests \\ There are no conflict of interests.}

\section{Funding}

This work was supported by research grants from the Daegu Catholic University in 2017.

\section{ORCID iD}

Kyungjae Lee

https://orcid.org/0000-0002-6811-1212

\section{REFERENCES}

Ahn, J. B. (2013a). A study on kindergarten teachers' perception toward preschool-age children who stutter. Journal of Speech-Language and Hearing Disorders, 22(1), 235-252.

Ahn, J. B. (2013b). A study of special-education teacher's recognition of school-age students who stutter. Journal of Speech-Language and Hearing Disorders, 22(2), 23-42.

Benecken, J. (1995). Proceedings of the first world congress on Fluency Disorders: On the Nature and Psychological Relevance of a Stigma: The "Stutterer" or What Happens, When "Grace Falls." Munich: International Fluency Association.

Burley, P. M. \& Rinaldi, W. (1986). Effects of sex of listener and of stutterer on ratings of stuttering speakers. Journal of Fluency Disorders, 11(4), 329-333.

Chon, H. C. (2016a). Self-reactions of the public toward people who stutter: Age and sex differences. Communication Sciences and Disorders, 21(2), 371-381.

Chon, H. C. (2016b). Beliefs and knowledge of the public about people who stutter: Age and sex comparisons. Communication Sciences and Disorders, 21(3), 538-551.

Cooper, E. B. \& Cooper, C. S. (1996). Clinician attitudes towards stuttering: Two decades of change. Journal of Fluency Disorders, 21(2), 119-135.

Crowe, T. A. \& Walton, J. H. (1981). Teacher attitudes toward stuttering. Journal of Fluency Disorders, 6(2), 163-174.

Evans, J. \& Williams, R. (2015). Stuttering in film media-investigation of a stereotype. Procedia-Social and Behavioral Sciences, 193, 337.

Han, M. A. (2015). Stuttering perception of elementary school children using POSHA-S (Public Opinion Survey of Human Attributes-Stuttering) (Unpublished master's thesis). Daegu Catholic University, Gyeongsan.

Healey, E. C., Gabel, R. M., Daniels, D. E., \& Kawai, N. (2007). The effects of self-disclosure and non self-disclosure of stuttering on listeners' perceptions of a person who stutters. Journal of Fluency Disorders, 32(1), 51-69.

Irani, F. \& Gabel, R. (2008). Schoolteachers' attitudes towards people who stutter: Results of a mail survey. Canadian Journal of Speech-Language Pathology and Audiology, 32(3), 129-134.

Kim, J. E. (2016). Teacher's perception, attitude and coping in preschool child with stuttering (Unpublished master's thesis). Myongji University, Seoul.

Kim, Z. Y., Lee, K. J., Choi, S. H., \& Choi, C. H. (2018). Changes in kindergarten teachers' perception toward stuttering according to stuttering education. Journal of Speech-Language and Hearing Disorders, 27(4), 91-99.

Klassen, T. R. (2002). Social distance and the negative stereotype of people who stutter. Canadian Journal of Speech-Language Pathology and Audiology, 26(2), 90-99.

Lee, K. (2013). Perception toward stuttering by teachers in Daegu area. Communication Sciences and Disorders, 18(4), 447-458.

Lee, K. \& Manning, W. H. (2010). Listener responses according to stuttering self-acknowledgment and modification. Journal of Fluency Disorders, 35(2), 110-122.

Lee, K. \& St. Louis, K. O. (2014). Proceedings from the annual meeting of the Korean Academy of Speech-Language Pathology and Audiology: Primary School Teachers' Attitudes Toward Stuttering Using POSHA-S. Gyeongsan, Gyeongbuk: Daegu Catholic University.

MacKinnon, S. P., Hall, S., \& MacIntyre, P. D. (2007). Origins of the stutter- 
ing stereotype: Stereotype formation through anchoring-adjustment. Journal of Fluency Disorders, 32(4), 297-309.

Shimada, M., Toyomura, A., Fujii, T., \& Minami, T. (2018). Children who stutter at 3 years of age: A community-based study. Journal of Fluency Disorders, 56, 45-54.

Sim, H. S. (2000). A study on stereotypes of the Korean male adults who stutter. Communication Sciences and Disorders, 5(1), 1-7.

St. Louis, K. O. (2011). The Public Opinion Survey of Human Attributes-
Stuttering (POSHA-S): Summary framework and empirical comparisons. Journal of Fluency Disorders, 36(4), 256-261.

White, P. A. \& Collins, S. R. C. (1984). Stereotype formation by inference: A possible explanation for the "stutterer" stereotype. Journal of Speech, Language, and Hearing Research, 27(4), 567-570.

Woods, C. L. \& Williams, D. E. (1976). Traits attributed to stuttering and normally fluent males. Journal of Speech and Hearing Research, 19(2), 267278. 


\section{Bipolar Adjective Scale}

말더듬는 사람에 대한 본인의 평소 생각을 솔직하게 표시해 주세요.

\begin{tabular}{c|c|c|c|c|c|c|c|c}
\hline & 매우 많이 & 많이 & 약간 & 중간 & 약간 & 많이 & 매우 많이 & \\
\hline 수줍어함 & & & & & & & & 대담함 \\
\hline 조심함 & & & & & & & & 자신감 있음 \\
\hline 긴장함 & & & & & & & & 이완됨 \\
\hline 민감함 & & & & & & & & 둔감함 \\
\hline 안절부절함 & & & & & & & & 침착함 \\
\hline 소극적 & & & & & & & & 적극적 \\
\hline 회피적 & & & & & & & & 사교적 \\
\hline 두려워함 & & & & & & & & 확신에 참 \\
\hline 내향적 & & & & & & & & 외향적 \\
\hline 주저함 & & & & & & & & 도전적 \\
\hline
\end{tabular}

